\title{
PP-03 UNRAVELING THE CLINICAL ESTABLISHMENT ACT IN CHHATTISGARH: A CAMPAIGN AND A STUDY
}

Sulakshana Nandi, Deepika Joshi, Rajesh Dubey. PHRN - Public Health Resource Network, Raipur (Chhattisgarh), India

\subsection{6/bmjgh-2016-EPHPabstracts.54}

Background Chhattisgarh government passed the Chhattisgarh state Clinical Establishments Act (CEA) in 2010 after consultations with the private sector and civil society. A number of provisions were slashed in the final Act due to pressure from the private sector. Rules were notified in August 2013. The CEA is unique in its provisions for patients rights and grievance redressal. Since 2014, the Public Health Resource Network (PHRN) has collaborated with various health rights organisations in a campaign aimed at increasing awareness about the CEA, monitoring and documenting implementation and denial of patients rights, bringing together views of various stakeholders and undertaking related advocacy with the government. Methods Data were collected through interviews (with eight Chief Medical and Health Officers/Nodal Officers, state nodal officer and nine private providers), group discussions (with civil society members during eight district consultations and two state-level workshops, nonprofit private providers and private doctors in one district) and analysis of state and district level data and 24 media reports. A semi-structured interview guide for government functionaries and doctors explored their perceptions, process of CEA implementation, and challenges faced. A checklist for civil society explored their awareness regarding the CEA, and civil society's experience in utilising and monitoring it. Thematic analysis was undertaken. Findings were presented periodically to all stakeholders.

Findings Until October 2015, 7,414 applications have been received, all of which have not undergone full registration process; $21 \%$ recommended for license and many declared unfit for licensing. Process of registration was initiated through orientations by district health administration, media advertisements and the Indian Medical Association (IMA). The applications accepted online and offline and inspection teams formed. The process seems to depend heavily on the Chief Medical and Health Officers and district committee, and flexibility is the norm. Government facilities are deemed as licensed without any process.

Private-for-profit practitioners see the CEA as interference and harassment from government. They complain of delays, from getting mandatory certificates to licensing. They threaten that they may have to increase rates for treatment to cater to the standards and demand that government facilities should adhere 
to standards too. The nonprofit private sector has been facing problems with licensing their nurse-run outreach clinics.

The district health administration perceives CEA as lots of extra work without appointment of any dedicated staff. They maintain that compliance to standards is too rigid and difficult to implement, most difficult being infrastructure standards. Hence flexibility in standards, depending on the district location is the norm. Moreover, the specialists are lending their name to 15-20 Clinical Establishments (CEs), especially in underserved districts.

Members of civil society and various community members shared their concerns regarding the lack of attempt by the government to spread awareness regarding the CEA, and lack of transparency regarding information about the facilities under CEA despite such provisions in the Act. Civil society members are not part of any of the mandated committees. Attempts to register complaints have been challenging and people are eager to use the CEA to deal with problems related to out-of-pocket payments and denial of services under the state insurance schemes (RSBY/MSBY). Through campaign's efforts, the media have been active in reporting gaps in CEA implementation.

Discussion \& recommendations Regulation of CEs is important and the passing of the Act is an important step. However, the CEA and its provisions need also to be properly implemented. Currently there are inordinate delays in the licensing process, for which dedicated staff and budget need to be provided. Flexibility in standards, if accorded to facilities, needs to be documented with approval from a higher authority. The laxity is creating space for the for-profit private sector to constantly push for relaxing the standards; with the Indian Medical Association already negotiating CEA and RSBY provisions jointly with the government.

The government needs to become more active in disseminating information about the Act amongst the public. The systems for monitoring the CEs once licensed have to be established, with scope for participation by the user community and civil society. Provisions under CEA and RSBY have to be integrated for effective monitoring of the clinical establishment.

There needs to be greater transparency in terms of display of the charter of patients rights at the facility and public access to information on CEs. Civil society members need to be included as part of the committees, that is already a part of the National Act. It is crucial that public facilities too should plan for improving and upgrading themselves as part of licensing.

The campaign in Chhattisgarh saw active involvement of civil society organisations and media, through awareness building and advocacy. The Act continues to provide opportunity for monitoring of the private sector in terms of patients rights and schemes like RSBY of which the private sector has been the biggest beneficiary. The on-going action research has helped to identify issues of concern that need to be further pursued for advocacy and action for better implementation of the CEA and realization of patients rights.

Grant funding (Oxfam India, New Delhi) for research but no other competing interests. 